\title{
Supporting information for: Revisiting OPLS-AA Force Field for Simulation of Anionic Surfactants in Concentrated Electrolyte Solutions
}

Safwat Abdel-Azeim

${ }^{1}$ Center for Integrative Petroleum Research (CIPR), College of Petroleum Engineering and Geosciences, King Fahd University of Petroleum and Minerals (KFUPM), Dhahran 31261, Saudi Arabia.

Table S1: Charges of $\left(\mathrm{CH}_{2} \mathrm{SO}_{4}\right)^{-1}$ head group of Dodecyl sulfate surfactant calculated at (MP2/cc-PVTZ (-f) level of theory using different population analysis. The atom types are also shown for SDS-head group.

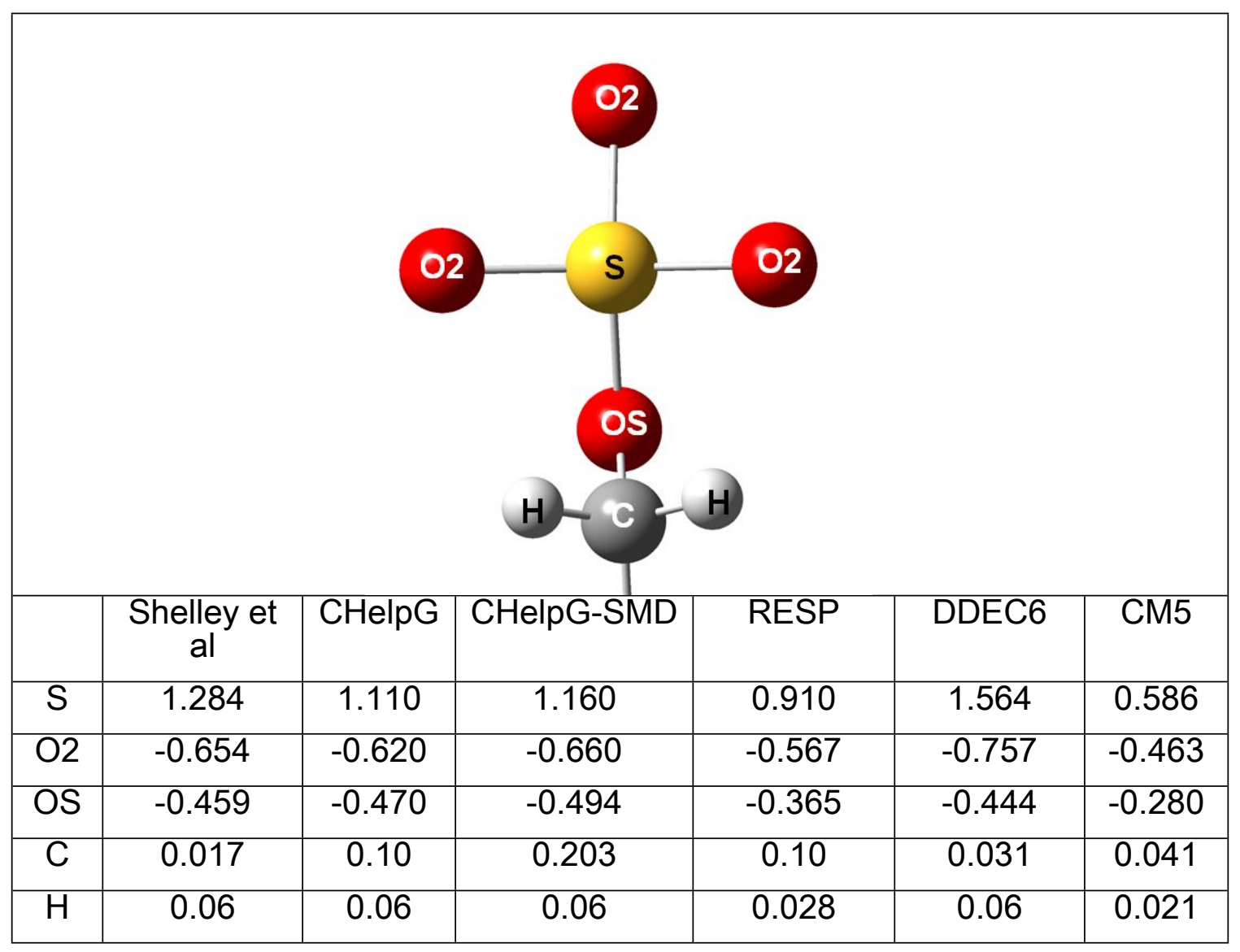




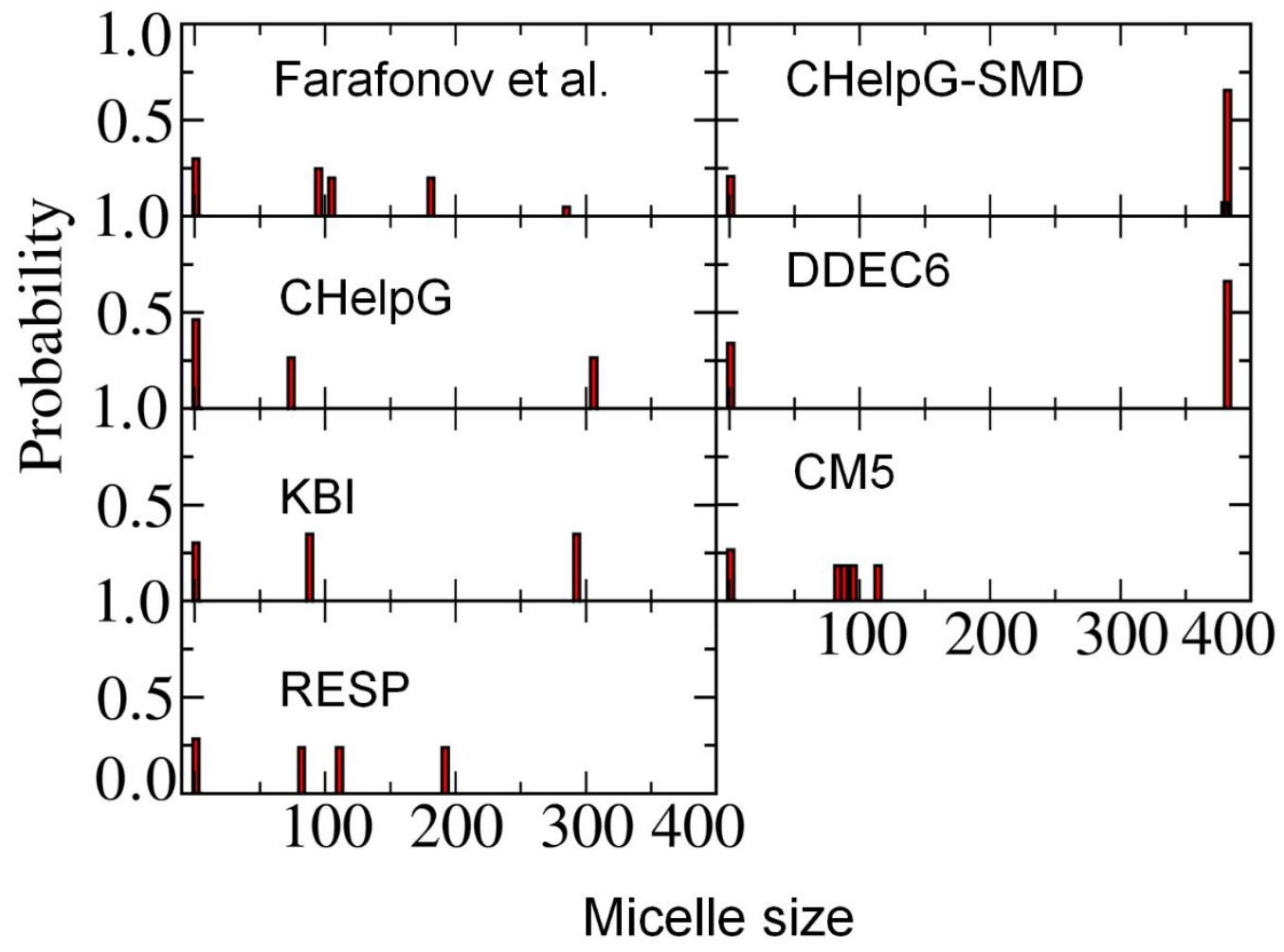

Figure S1: SDS-micelle size distribution normalized by the average micelle size calculated for the last $0.7 \mu \mathrm{s}$ of MD simulations using different parameter sets. 

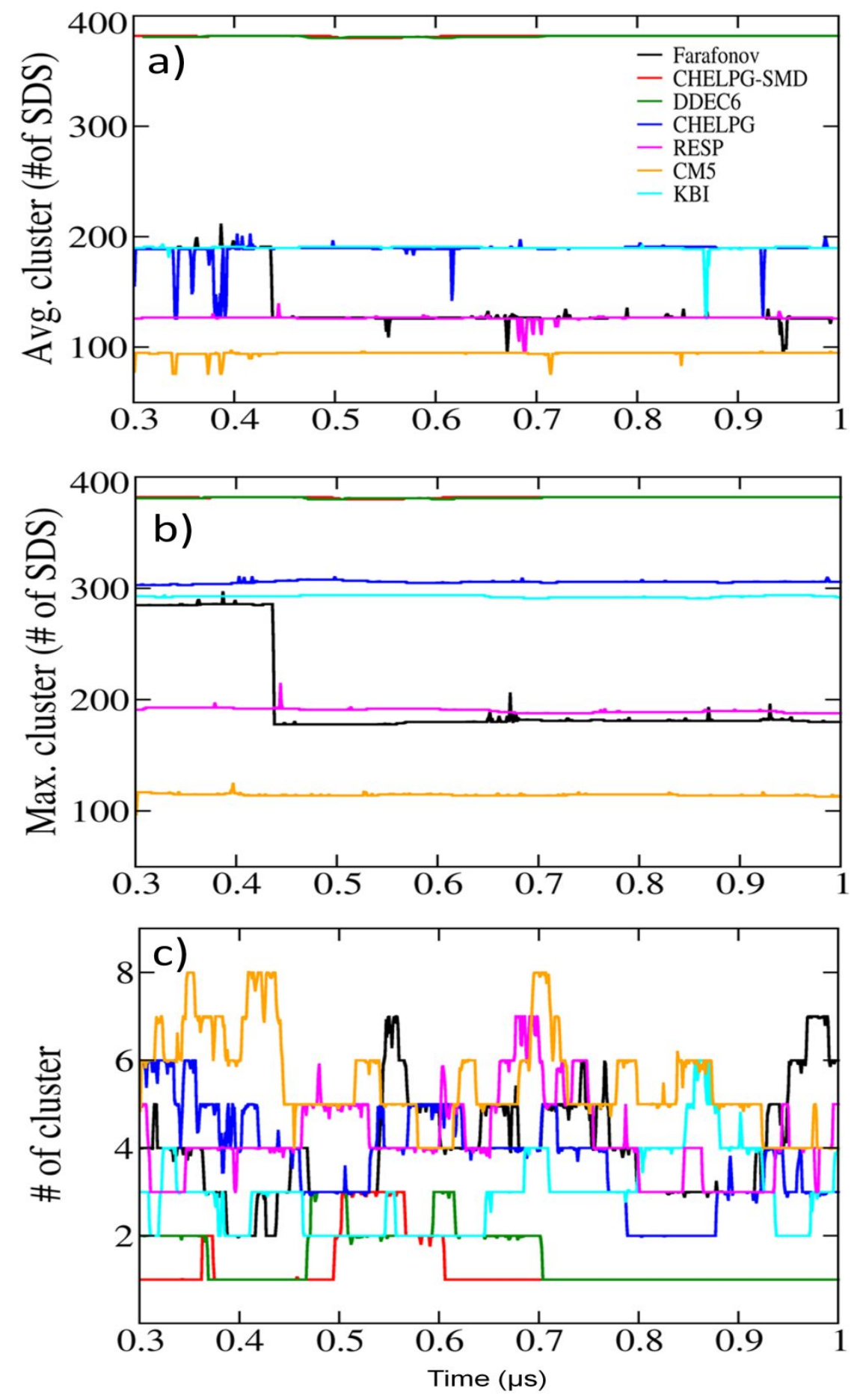

Figure S2: Time evolution of a) the average cluster size, b) the size of the largest cluster, and c) the number of clusters formed along $0.7 \mu$ s time of simulation using different set of charges, averaged every $1 \mathrm{~ns}$. We discarded the first $300 \mathrm{~ns}$ as an equilibration period. 


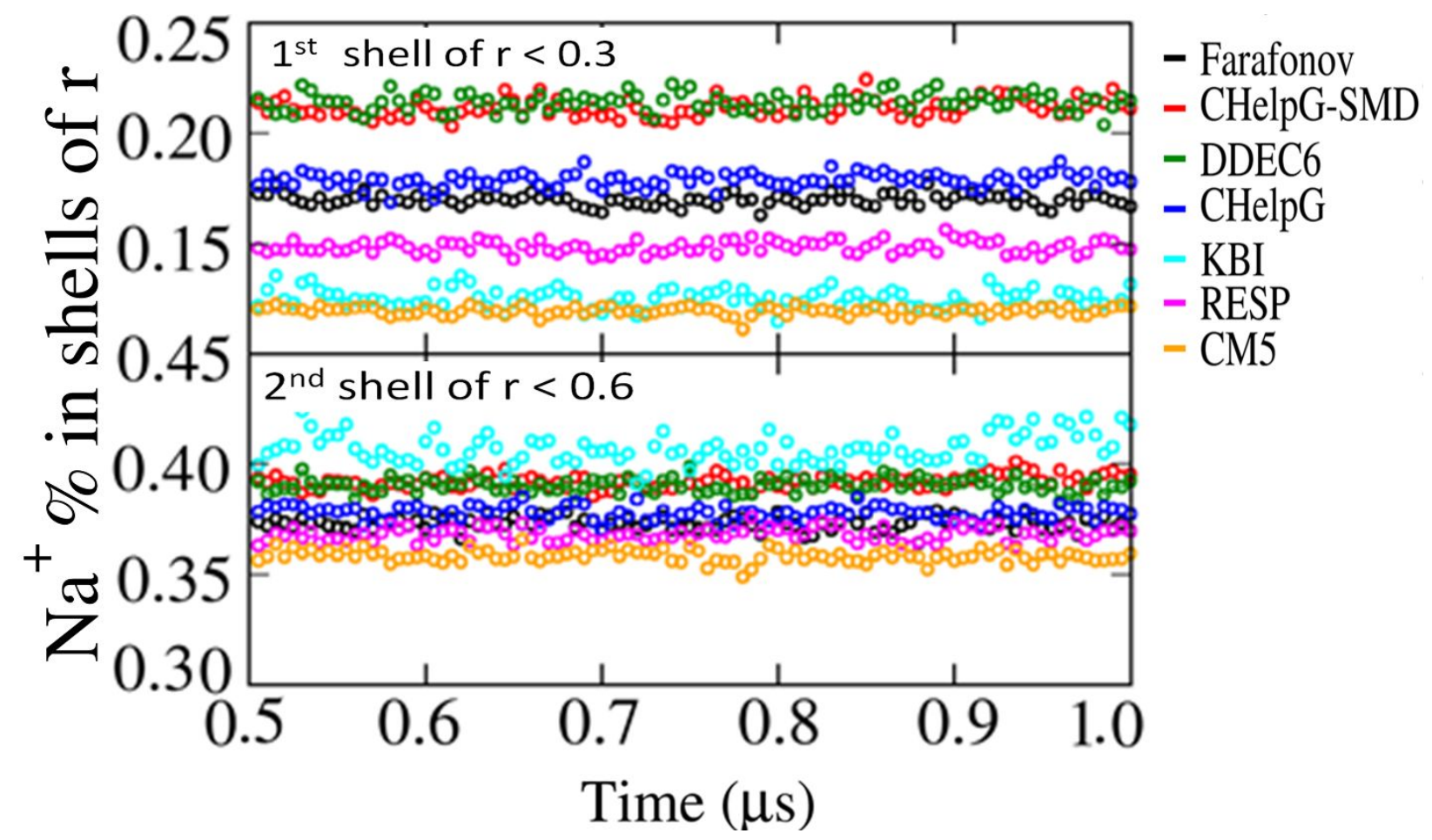

Figure S3: The dynamics of the percentage of $\mathrm{Na}^{+}$condensed on the micelle surface within the first two RDF shells calculated between the ionic oxygens of SDS-head group and sodium ions over the last $0.5 \mu \mathrm{s} . r$ is the spherical distance between SDS-ionic oxygens and sodium ions. 
a)

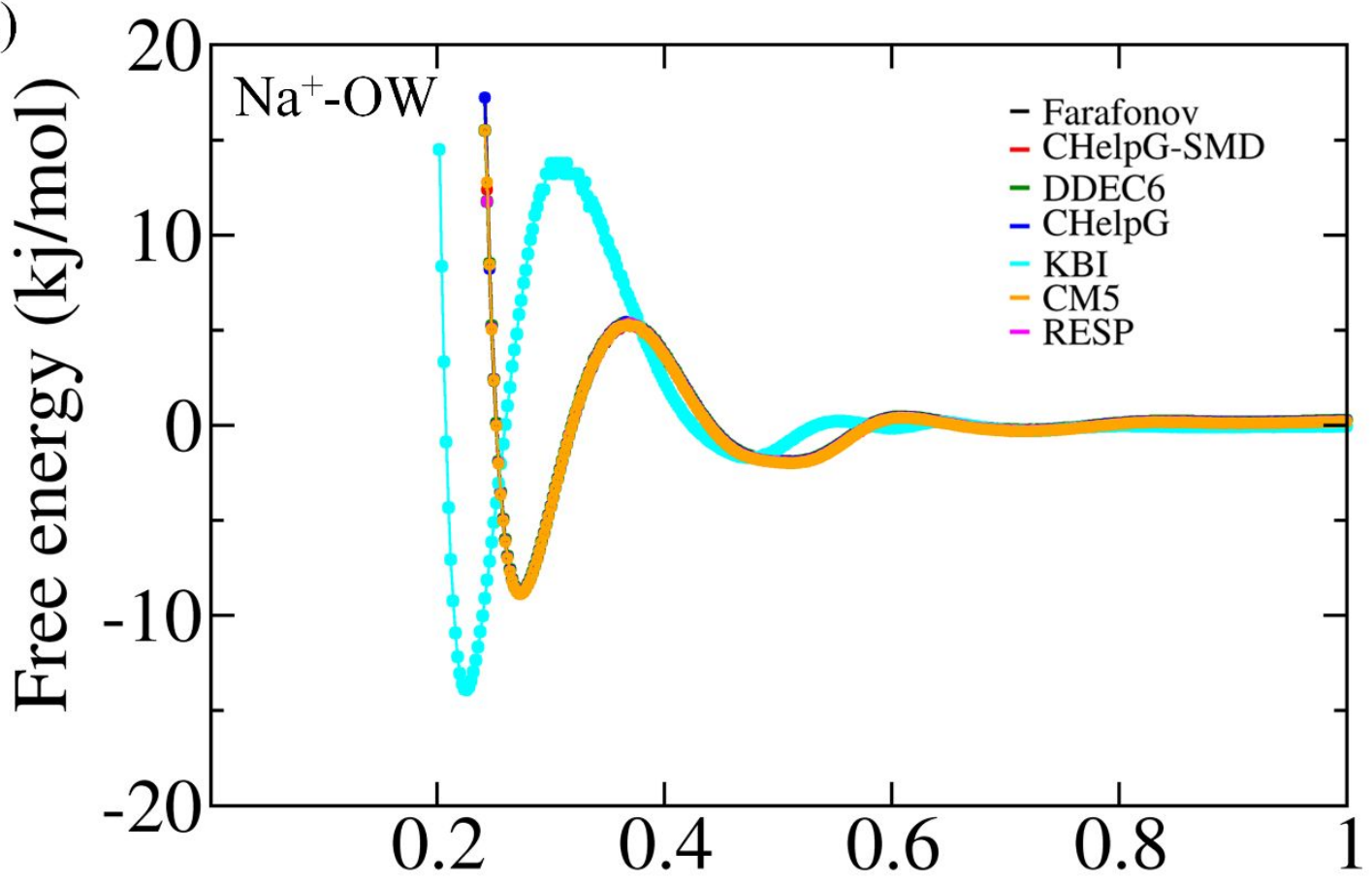

b)

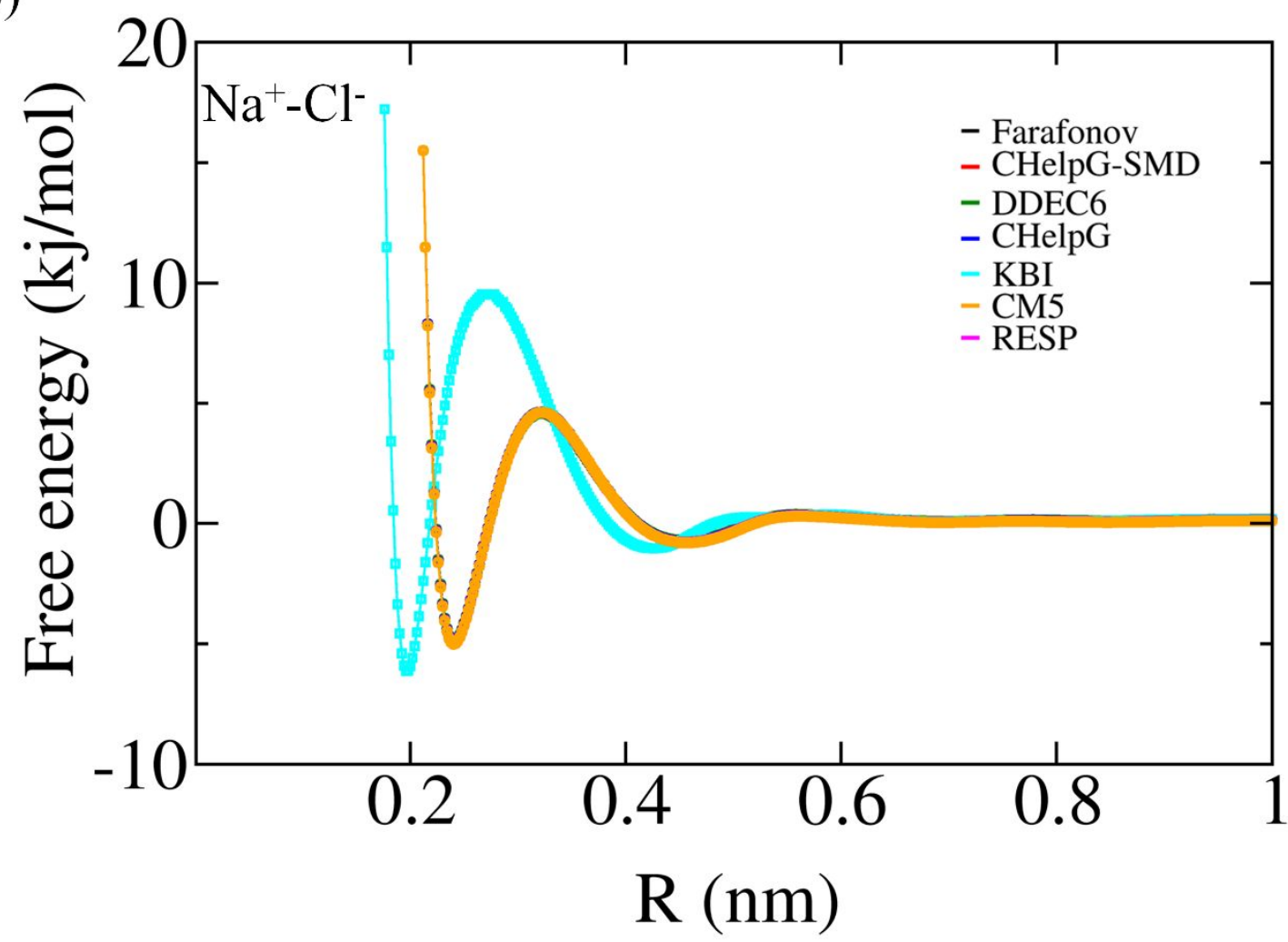

Figure S4: Potential mean force (PMF) of Na-OW (a), and $\mathrm{Na}-\mathrm{Cl}(\mathrm{b})$ interactions based on their radial distribution function $(g(r))$. PMF is calculated based on; $P M F=-K_{B} T \ln (g(r)),{ }^{1-3}$ here $K B$ is Boltzman's constant, $T$ is the simulation temperature, and $g(r)$ is the radial distribution 
function between $\mathrm{Na}-\mathrm{OW}$, and $\mathrm{Na}-\mathrm{Cl}$.

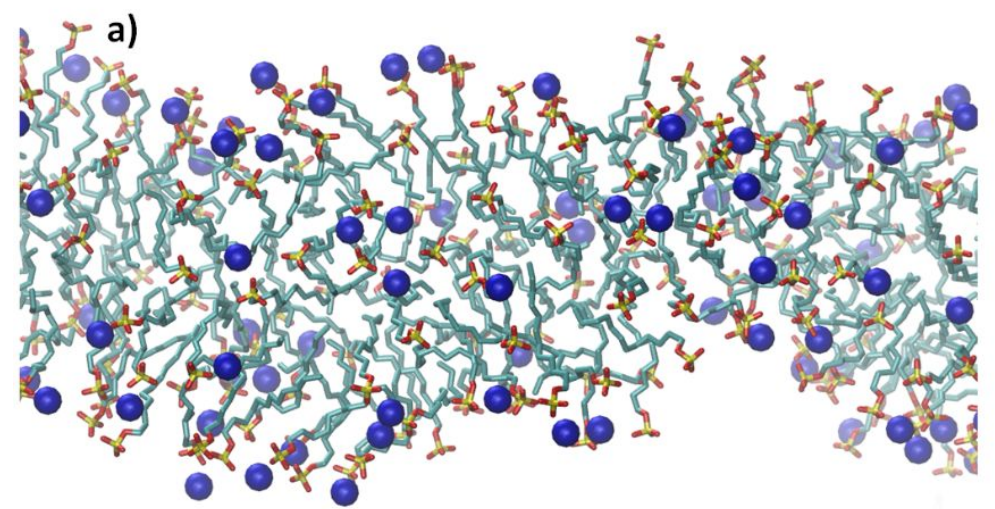

b)

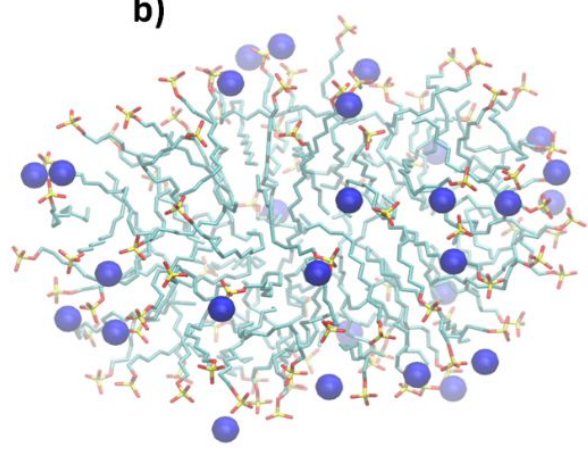

Figure S5: Final snapshot of layer simulated using Chelpg CM5 (b) set of charges.

ions are shown spheres, SDS surfactant is represented in Color code; S:yellow, and Hydrogen are removed for

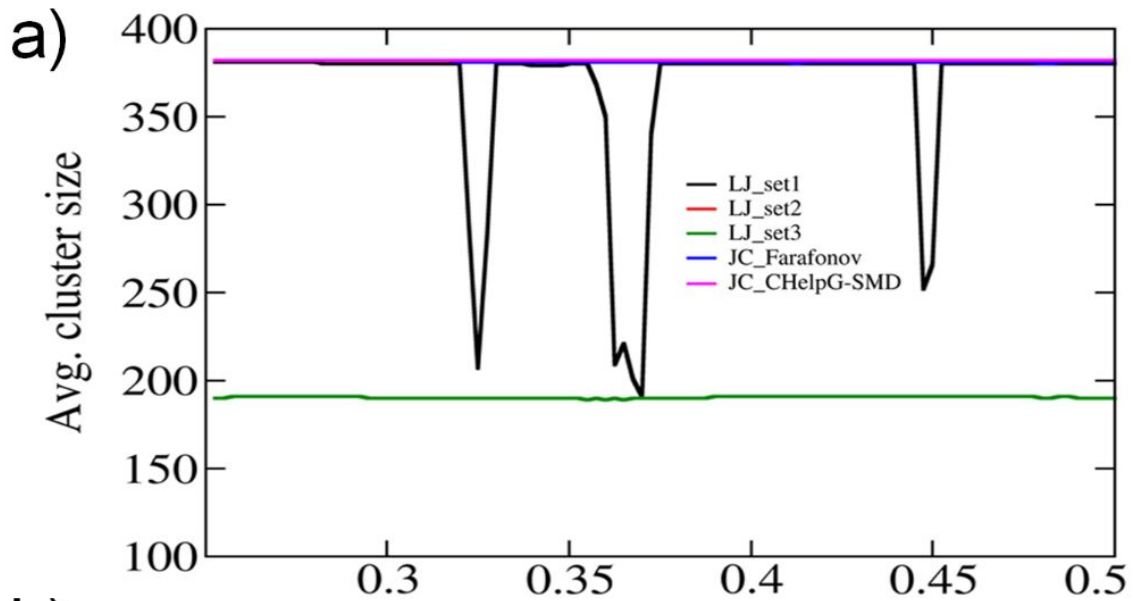

SDS-bifor $1 \mu \mathrm{s}$ (a) and atomic Sodium as blue

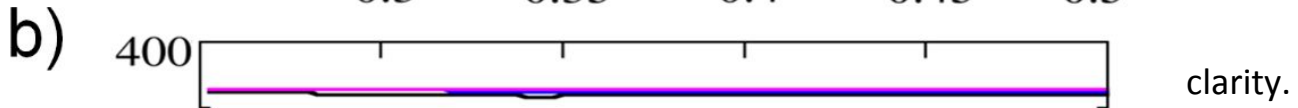

sticks.

C:cyan, o:red.

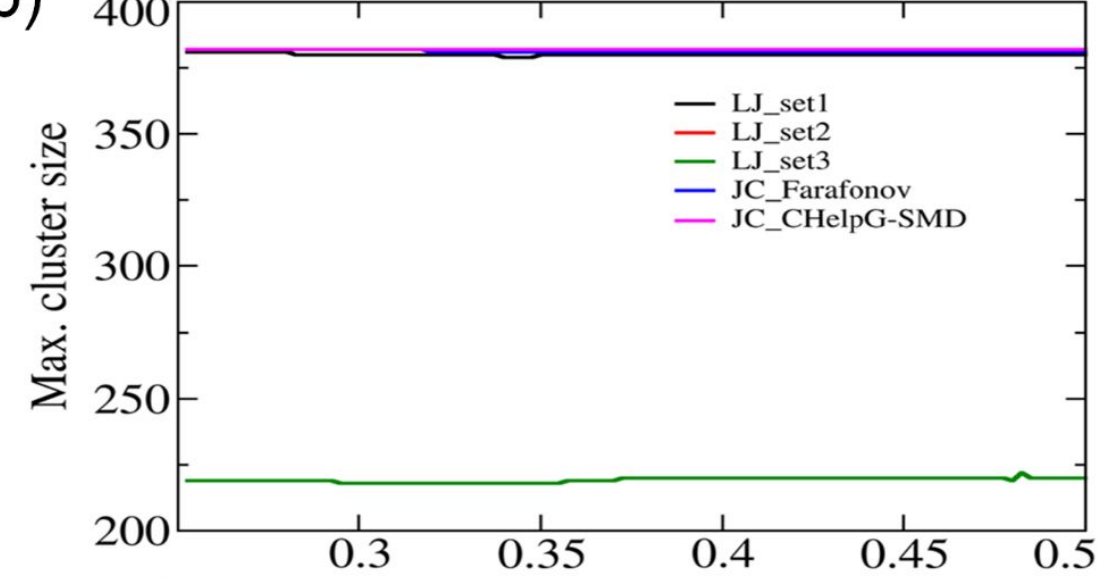

c)

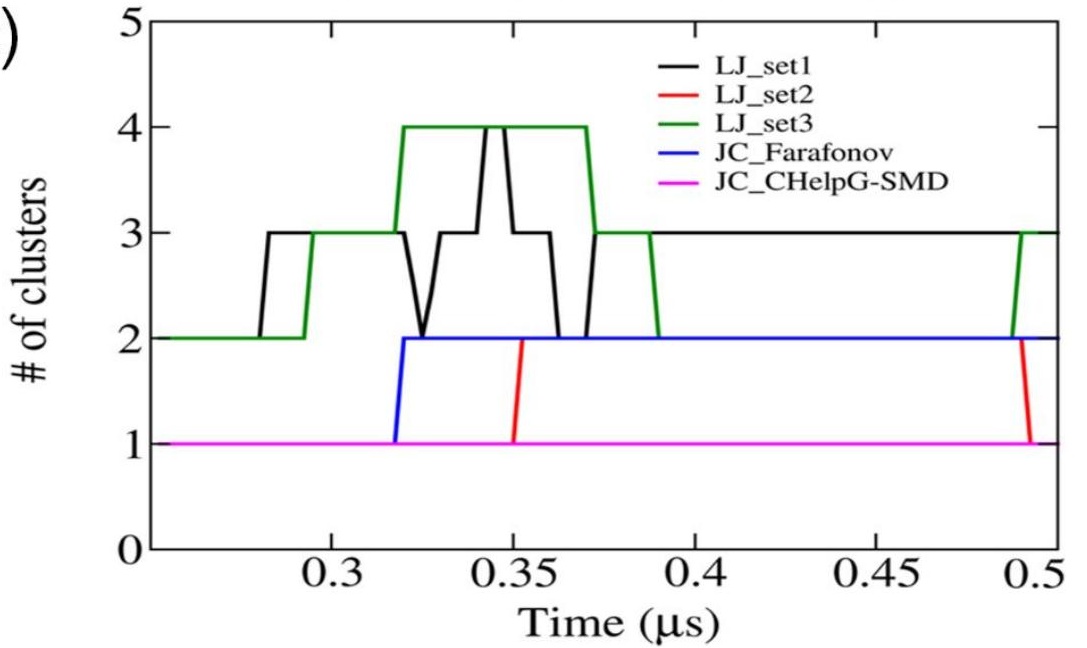


Figure S6: Time evolution of a) the average cluster size, b) the maximum cluster size, and c) the number of clusters formed along $0.25 \mu$ S SDS-AA simulations using different set of SDS-head group LJ parameters (namely, the ionic oxygen LJ parameters), and Joung \& Cheatman parameters of sodium ions in combination of Farafonov and CHelpG-SMD charges. We discard the first $0.250 \mu$ s as an equilibration period.

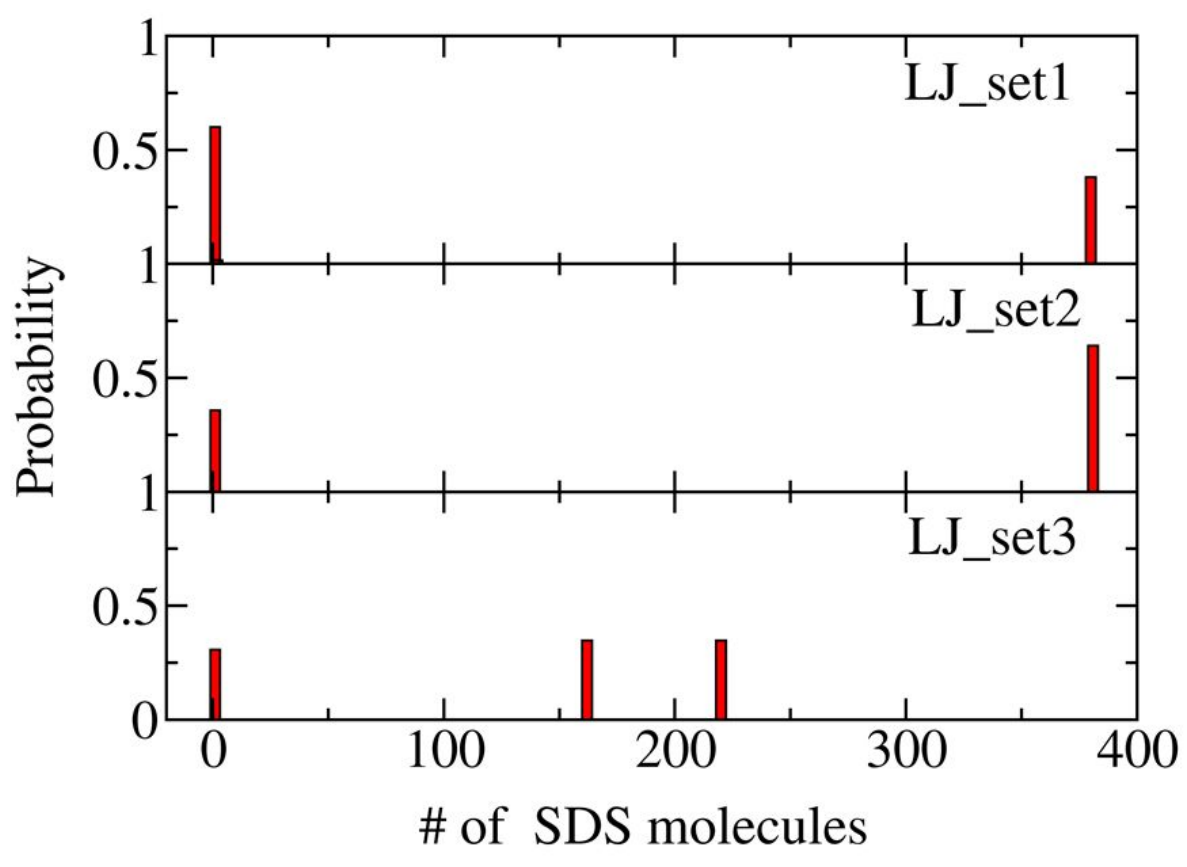


Figure S7: SDS-micelle size distribution normalized by the average micelle size over 0.25 us of

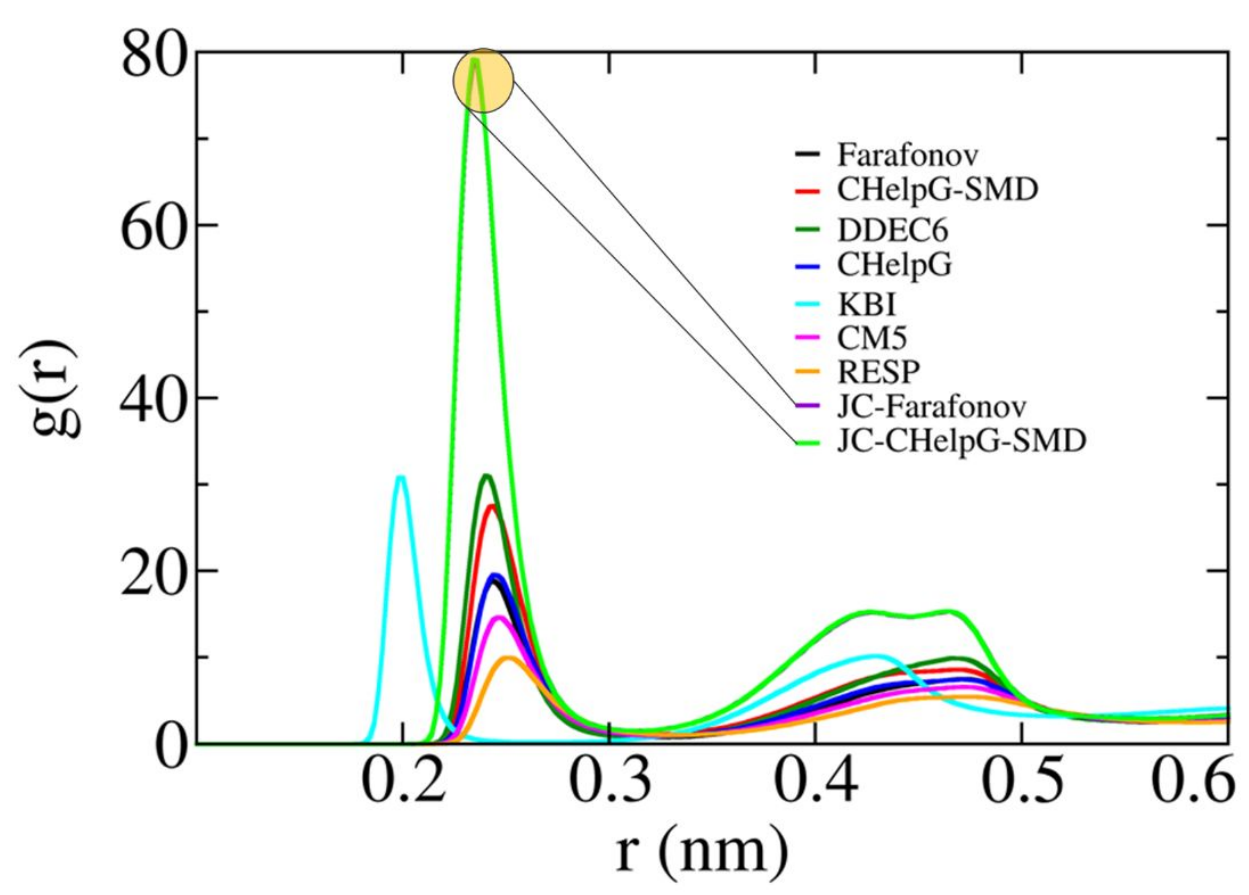

MD

simulations using the three LJ parameters of the ionic oxygens of SDS-head group.

Figure S8: Radial distribution function $(\mathrm{g}(\mathrm{r}))$ between $\mathrm{Na}^{+}$(Åqvist parameters) and SDShead-group ionic-oxygen atoms for all tested charge sets, and Farafonov, CHelpG-SMD, with Joung \& Cheatham parameters of $\mathrm{NaCl}$. SPC model was used for Water molecules. 

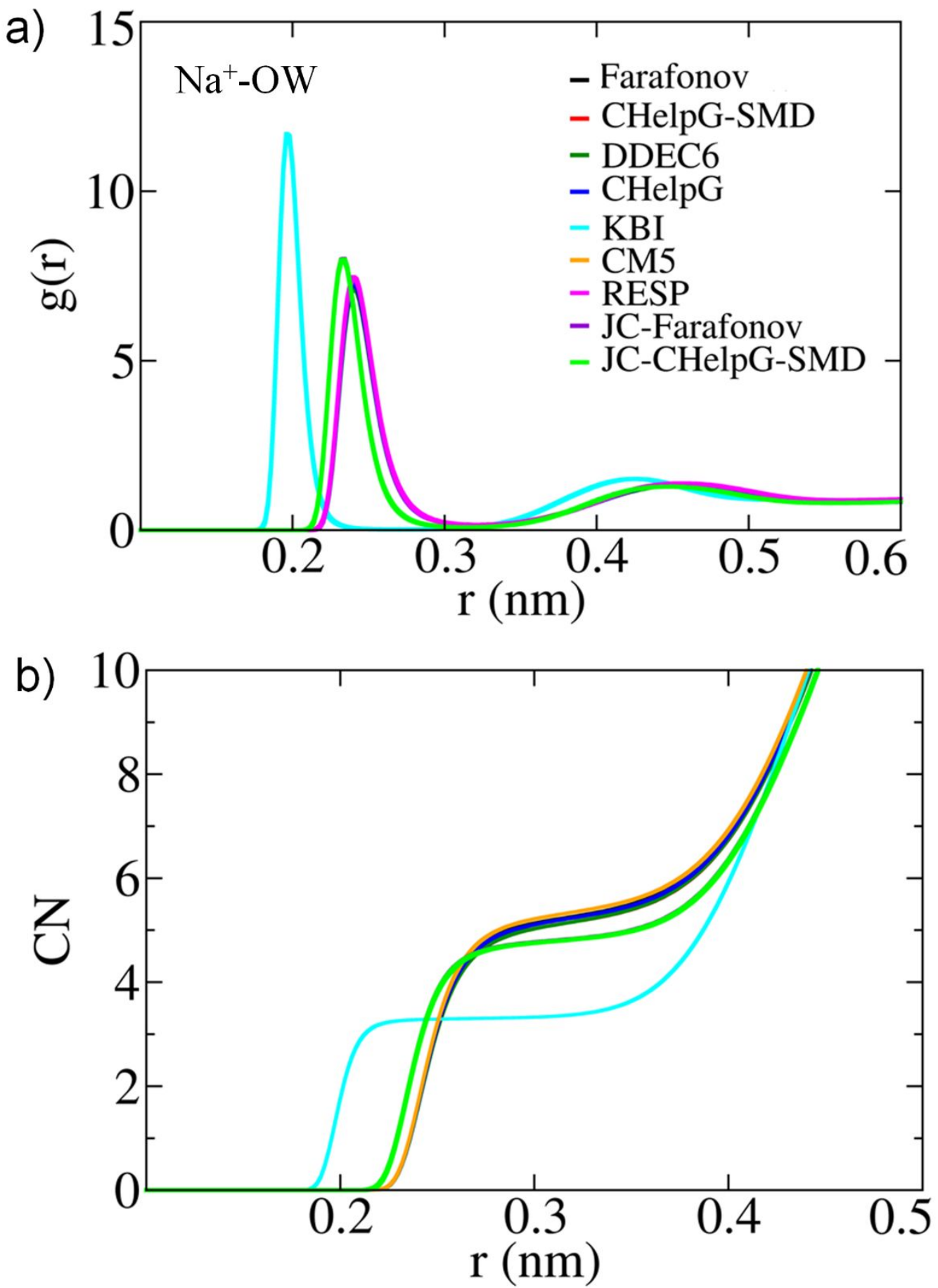

Figure S9: a) Radial distribution function $(g(r))$ between $\mathrm{Na}^{+}$and $\mathrm{OW}$ calculated for all the charges sets and Joung \& Cheatham (with Farafonov and CHelpG-SMD charges). b) Coordination number $(\mathrm{CN})$ of $\mathrm{Na}-\mathrm{OW}$ estimated as the integration of $(g(r))$ between $\mathrm{Na}^{+}$ and OW calculated for all the charges sets, and Joung \& Cheatham (with Farafonov and CHelpG-SMD charges). 

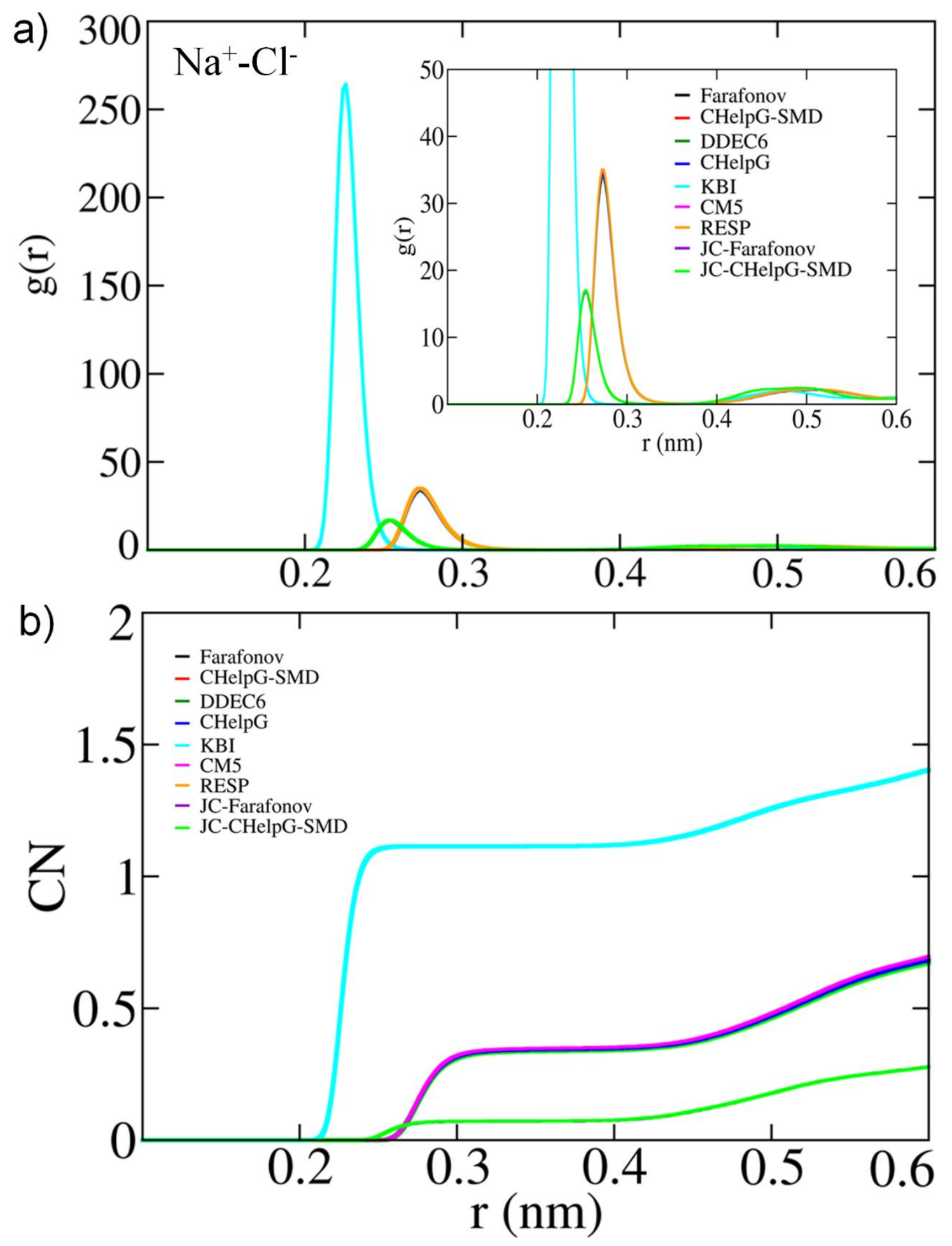

Figure S10: a) Radial distribution function $(g(r))$ between $\mathrm{Na}^{+}$and $\mathrm{Cl}^{-}$calculated for all the charges sets, and Joung \& Cheatham (with Farafonov and CHelpG-SMD). b) Coordination number $(\mathrm{CN})$ of $\mathrm{NaCl}$ estimated as the integration of $(\mathrm{g}(\mathrm{r}))$ between $\mathrm{Na}^{+}$and 
$\mathrm{Cl}^{-}$calculated for all the charges sets, and Joung \& Cheatham (with Farafonov and CHelpG-SMD charges).

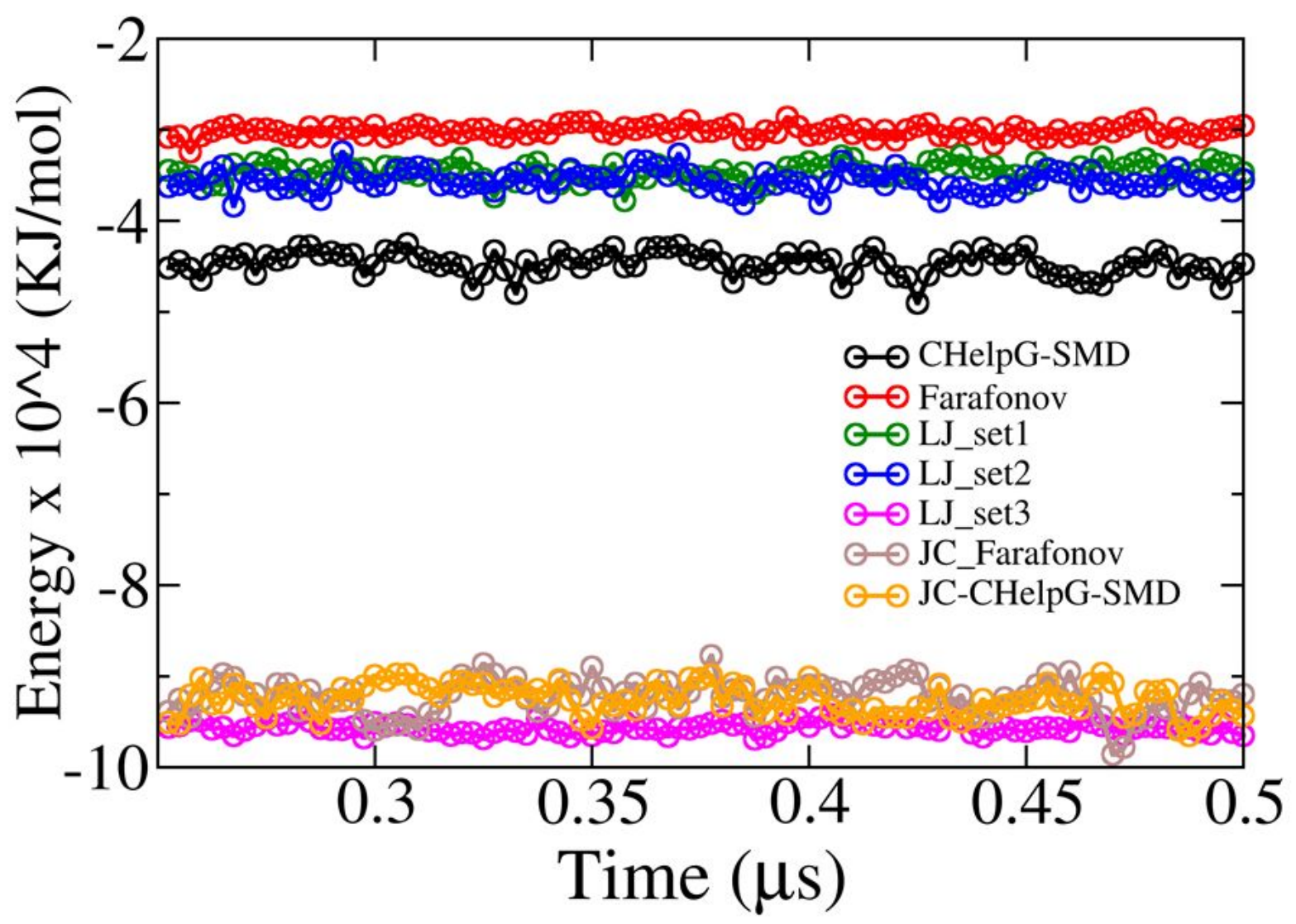

Figure S11: Interaction energies (Electrostatic and VDW) between $\mathrm{Na}^{+}$and SDS-head group $\left(\mathrm{SO}_{4}\right)^{-}$for Farafonov, CHelpG-SMD, Joung \& Cheatham , and the three LJ sets of the ionic oxygen of SDS-head group in combination with Farafonov set.

Table S2: The three LJ parameter sets used for the SDS-ionic oxygen in combination with Farafonov et al. (Shelley's charge set).

\begin{tabular}{|l|c|c|c|c|}
\hline & LJ_original & LJ_set1 & LJ_set2 & LJ_set3 \\
\hline Sigma (nm) & 0.315 & 0.296 & 0.315 & 0.315 \\
\hline $\begin{array}{l}\text { Epsilon } \\
(\mathrm{kJ} / \mathrm{mol})\end{array}$ & 0.8368 & 0.87864 & 1.00416 & 0.92048 \\
\hline
\end{tabular}



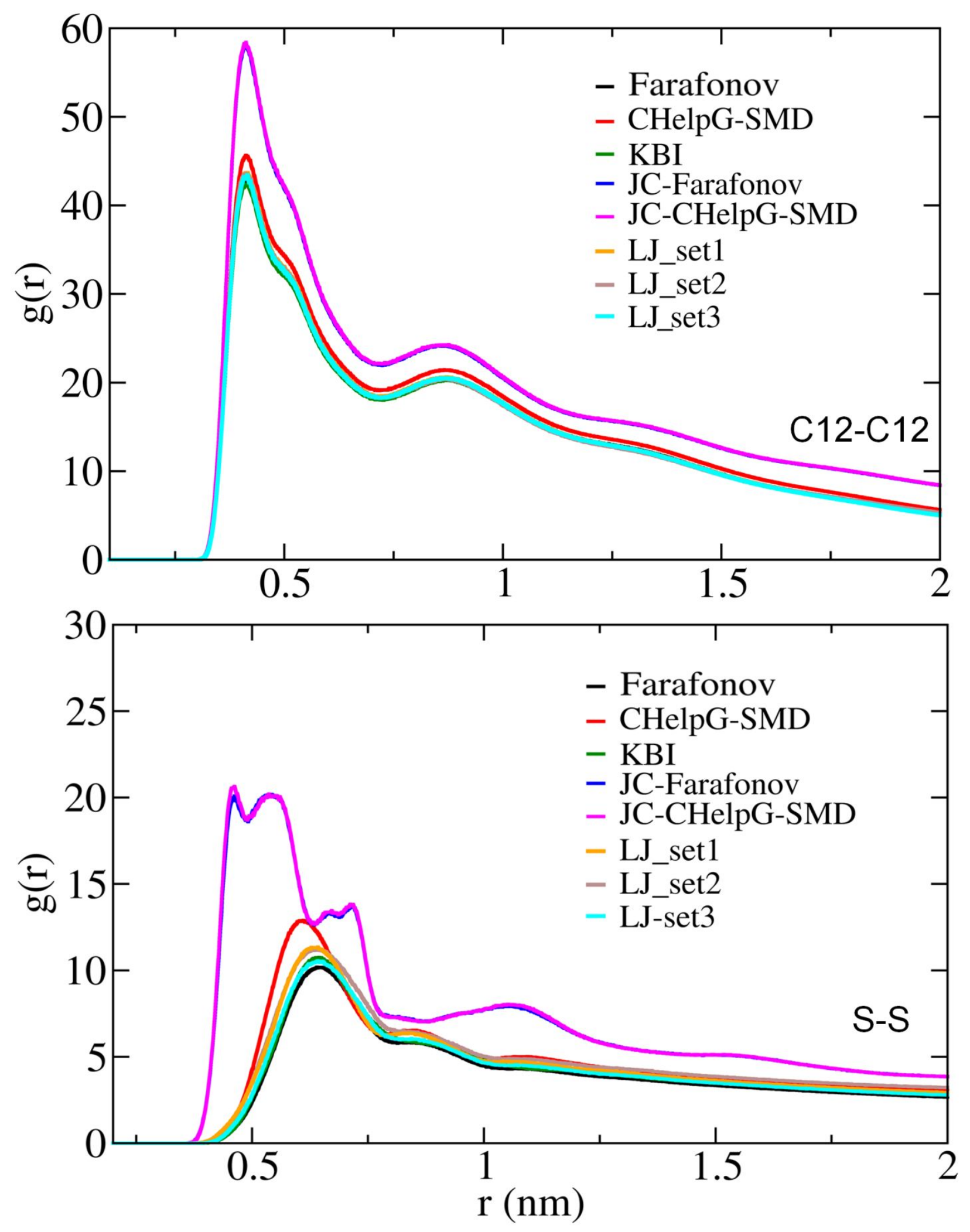
Figure S12: Radial distribution functions calculated between the SDS-terminal carbons (C12-C12) and sulfur-sulfur (S-S) atoms.

\section{References}

(1) Ghosh, T.; García, A. E.; Garde, S. Molecular Dynamics Simulations of Pressure Effects on Hydrophobic Interactions. J. Am. Chem. Soc. 2001, 123 (44), 1099711003.

(2) Yan, H.; Guo, X.-L.; Yuan, S.-L.; Liu, C.-B. Molecular Dynamics Study of the Effect of Calcium lons on the Monolayer of SDC and SDSn Surfactants at the Vapor/Liquid Interface. Langmuir 2011, $27(10), 5762-5771$.

(3) Abdel-Azeim, S.; Kanj, M. Y. Dynamics, Aggregation, and Interfacial Properties of the Partially Hydrolyzed Polyacrylamide Polymer for Enhanced Oil Recovery Applications: Insights from Molecular Dynamics Simulations. Energy Fuels 2018, 32 (3), 3335-3343. 